\title{
A Simple Four Quadrants Model to Monitor the Performance of Local Governments
}

\author{
Danilo Ballanti \\ Roberto Dispotico \\ Francesco Porcelli \\ Francesco Vidoli
}

CESIFO WORKING PAPER NO. 5062

CATEGORY 1: Public FinANCE

NOVEMBER 2014
An electronic version of the paper may be downloaded
- from the SSRN website: Www.SSRN.com
- from the RePEc website: Wwww.RePEc.org
- from the CESifo website: www.CESifo-group.org/wp




\title{
A Simple Four Quadrants Model to Monitor the Performance of Local Governments
}

\begin{abstract}
This paper, conducted as part of the research activities of SOSE S.p.A., develops a simple and innovative model to evaluate the performance of local government in the provision of local public services. The model employs a reduced set of information and fewer assumptions than traditional techniques such as Data Envelopment Analysis and Stochastic Frontier Analysis. The main idea is to base the model on the joint graphical analysis of standard expenditures needs and standard level of services both estimated using a reduced form approach derived from a general theoretical framework based on the interaction between the demand and the supply for local public services. Data about social care services provided by Italian municipalities in 2010 are used to test the model.
\end{abstract}

JEL-Code: H720, H770, H830.

Keywords: standard level of services, standard expenditure needs, performance, local governments, municipality, Italy.

\author{
Danilo Ballanti \\ SOSE - Rome / Italy \\ dballanti@sose.it \\ Francesco Porcelli \\ University of Exeter \\ Exeter / United Kingdom \\ fporcelli78@gmail.com
}

\author{
Roberto Dispotico \\ SOSE - Rome / Italy \\ rdispotico@sose.it \\ Francesco Vidoli \\ SOSE - Rome / Italy \\ fvidoli@sose.it
}

Preliminary version (11 October 2014)

This document does not necessarily reflect the official opinion of SOSE - Soluzioni per il Sistema Economico S.p.A. and commits only the authors. SOSE - Soluzioni per il Sistema Economico S.p.a. is a company, owned both by the Italian Ministry of Economy and Finance (88\%) and Bank of Italy (12\%), specialised in the provision of statistical and econometric analysis in any field of the private and public sector. Since 2011 SOSE, among its activities, elaborates the econometric models for the the evaluation of the standard expenditure needs of Italian local governments. 


\section{INTRODUCTION}

This paper provides two contributions: as a first result we show that the common econometric techniques employed to estimate local governments' standard expenditure needs can be usefully adapted to measure the corresponding standard level of local public ${ }^{1}$ services. Subsequently, introducing a simple Four Quadrant Model, we propose to evaluate the performance of each local government through the joint graphical analysis of two measures: the expenditure gap which corresponds to the difference between actual and standard expenditures, and the output gap which corresponds to the difference between the actual and standard level of services. As a final result we can identify four types of local governments (LGs) (see Figure 1): over-standard LGs, whether both the output gap and the expenditure gap are positive; under-standard LGs, when both the output gap and the expenditure gap are negative; efficient LGs, in case the output gap is positive and the expenditure gap is negative; non-efficient LGs, whether the expenditure gap is positive and the output gap is negative.

The motivation for this paper comes from questioning whether standard expenditure needs (SEN) could be used to monitor local LGs efficiency in the provision of local services, a question to which our initial answer was negative.

Our negative answer hinges on the argument that the crude comparisons between standard expenditures and historic expenditures do not provide enough information to infer the ability of LGs and the effort they exert in the production of local services for two main reasons: the level of actual expenditures for a particular year may be affected by special events beyond the control of LG such as earthquakes, floods etc.; and most importantly, the level of actual expenditures is influenced by quantity and/or the quality of services produced which can be above or below the standard level compatible with the standard expenditures. The model developed in this paper aims at overcoming these difficulties making possible the comparison between standard and historic expenditures measuring, and at the same time, the performance of LGs in the provision of local services.

Over the last twenty years, the methodologies proposed in the economic literature to measure and monitor the performance of LG have never been based on SEN. Instead it is possible to observe an increasing use of techniques that allows the direct estimation of efficiency (technical and/or allocative) using parametric and non-parametric methods such as Stochastic Frontier Analysis (SFA) and Data Envelopment Analysis (DEA), methods which evaluate the distance of each LG from a best practice frontier estimated in terms of cost function or production

\footnotetext{
${ }^{1}$ In the rest of the paper the term "public" is used to identify services provided by public bodies even if the services or the goods provided are excludable and/or rival in the consumption.
} 
function (among others, see, for example: Grossman at al. (1999), Worthington and Dollery (2000), Afonso and Fernandes (2006)).

In early studies, the SFA have been applied to examine municipal service efficiency in terms of cost (see e.g. Deller 1992) or production (see e.g. Jayasuriya $\&$ Wodon 2003), while from '90s, the most employed approach to investigate the local public sector efficiency has been the nonparametric techniques such as Data Envelopment Analysis (DEA) (see e.g. Cook et al. 1990, Prieto \& Zofio 2001, Afonso \& Fernandes 2006).

Moreover, from a territorial point of view, it can be pointed out that the totality of the research in an international context focus only on a sample of Local Governments (e.g. 235 Belgian Municipalities, Vanden Eeckaut et al. 1993; 589 Belgian municipalities, De Borger \& Kerstens (1996); 262 Italian municipalities, Boetti et al. 2012; 15 Italian regions, Porcelli (2014); 111 Italina municipalities, Bergantino and Porcelli (2013)).

However, it is important to point out that, although these techniques are supported by robust economic principles, the massive use of DEA and SFA observed in the academic context is contrasted by the policymakers' reluctance to implement policy actions exclusively based on the results generated by these methodologies.

For example, the Comprehensive Performance Assessment (CPA) of English local governments was conducted from 2002 to 2008 by an independent auditing agency (Audit Commission) using a balanced scorecard methodology rather than DEA or SFA techniques ${ }^{2}$. CPA, based on a set of output measures named Best Value Practice Indicators (BVPI), and the judgment of inspectors, led to the annual publication of a ranking of local authorities, which continued for eight years from 2002 to 2008. This ranking assigned to each authority a number of stars ranging from five for performance excellence, to one for very poor performance. First and foremost, CPA was an incentive scheme whose primarily goal was to ensure that the increase of local expenditures decided by the central government after 2001 was converted into better services in terms of quantity and quality, to that end CPA was mainly a measure of output rather than a measure of efficiency as reported Porcelli (2011) and, as shown by Lockwood and Porcelli (2013), CPA failed in stimulating higher efficiency in the provision of local services since to achieve a good CPA score LGs increased simultaneously the level of output and the level of input measured in terms of local taxes. Nonetheless, to date, CPA is

\footnotetext{
2 In particular Haubrich and McLean [2006] and Martin et al. [2010] compare CPA with the assessment regimes adopted in Scotland and Wales that differently from England have developed assessment systems without published rankings of local authorities. Woods and Grubnic [2008] show the huge similarities between CPA and the Balanced Scorecard, a performance measurement method typically used to assess performance and stimulate efficiency improvement in private firms.
} 
the sole concrete example of an assessment system based on quantitative indicators designed to monitor the overall performance of local authorities.

Other examples of indicator systems are the Australian Review of Government Service Provision, a comprehensive assessment that provides performance information on 14 areas of public services; and the Denmark's system for monitoring municipal performance or Norway's KOSTRA System which collects information about local government performance.

The scarse use of DEA and SFA as a direct policy tool can be attributed, not only to the general reluctance expressed by policymakers towards statistical methods, but also to some of the limits of these techniques. As a first limitation there is the impossibility of extending the efficiency analysis beyond the regression sample, especially in case of SFA which is based on a parametric approach, thereby making difficult the performance assessment of those authorities that for statistical reasons are excluded from the sample. Moreover, as a second limitation, the correct evaluation of efficiency requires the imposition of several assumptions (larger in case of SFA than DEA) about the production function, assumptions that not always can be successfully verified making necessary the implementation of sophisticated procedures to ensure the robustness of the final results [Daraio and Simar (2007)].

Policymakers seems, instead, to accept effortless the adoption of statistical tools for the evaluation of standard expenditure needs (SEN), one of the building blocks of almost all systems of horizontal fiscal equalisation based on formula grants. In fact, many countries such as Australia, Denmark, Sweden, Finland and the United Kingdom compute SEN through statistical/econometric techniques based on two methodologies: the Representative Expenditure System (RES) and the Regression-based Cost Approach (RCA). In both cases the calculation of SEN is based on the concept that the financial needs of a local authority are subsequent to the territorial and socio-demographic characteristics of the resident population. The two methodologies, mentioned above, differ, however, in the way in which the determinants of SEN are selected and in the way in which the weight of each expenditure determinant is computed (for more details on the evaluation of SEN see OECD (1981), Blöchliger H. et al. (2007), Reschovsky A. (2007), Dafflon B. and Mischler P. (2007), SOSE (2014)).

Therefore, the main idea we try to develop in this paper is the implementation of a simple procedure to assess LGs performance using only the statistical and econometric tools usually adopted to compute formula-grants. To that end this paper is focused on the construction of a model where the evaluation SEN is complemented with the estimation of the standard level of services (SLS). So to describe the gap between standard expenditures and historic expenditures (once depurated from outlays generated by special circumstances beyond the control of 
LG such as natural disasters) as a good signal of the LGs performance as described at the beginning of the introduction.

In this way a single basic model can be used to measure simultaneously the SEN, the SLS and the performance of each LG allowing to separate normal situations, where the actual expenditure is above the standard level because the expenditure in excess is employed to produce services above the standard level, from alarming situation where, instead, the actual expenditure in excess with respect to the standard is wasted since the level of services provided is below the standard level in terms of quantity and/or quality.

Unlike the evaluation of SEN, the computation of SLS is a quite new exercise and very few useful references can be found in the literature. Regarding the measurement of the historical level of output, as we have already discussed before, the English experience is, at the moment, the most interesting one since over the last twenty years the outputs of English local authorities have been measured systematically by the Audit Commission (see Audit Commission 2009) through a range of indicators (over 200 active in 2009) known as BVPI ${ }^{3}$ and then used as one of the building blocks of the CPA.

However, the literature provides no help regarding the evaluation of the standard level of service; therefore we suggest to interpret the SLS as the level of services (in terms of quantity and quality) compatible with the demand for services expressed by the resident population of a specific territory, so to be able to estimate both SEN and SLS inside the same model generated from a theoretical framework based on the interaction between the demand and the supply for local public services. In this model, in line with the RCA methodology, SEN are computed considering an empirical model derived from the reduced form of the supply function, usually named expenditure function, where output variables are replaced by exogenous demand factors (e.g. variables related to distribution of the population by age). A similar reduced form approach is followed for the evaluation of the SLS through the estimation of an empirical model derived from the demand function where the cost of public services is replaced by the determinants of the supply (e.g. input prices). ${ }^{4}$ In this way we can compute, for each LG, a measure of standard expenditure and a measure of standard services which are highly compatible with each other since both measures are derived from the same set of variables and the same theoretical framework.

The adoption of a reduced-form approach for the estimation of the demand and the supply for local public services has multiple advantages (as discussed in more

\footnotetext{
${ }^{3}$ For example, among the output indicators for social care services are the number of elderly who require assistance at home in every 1000 inhabitants over 65 years of age (BPVI54); indicators related to environmental services include the percentage of recycled domestic waste (BPVI82a); and, lastly, indicators measuring the performance of general administrative services include the percentage of invoices paid within 30 days of receipt or within the agreed payment terms (BVPI8).

${ }^{4}$ See Section 2 for more details about the structure of the model.
} 
details in Section 2): first of all only exogenous variables are listed among the regressors thereby reducing the number of assumptions to be tested for the validity and the robustness of the final results; moreover, this approach is parsimonious in terms of the dimension of the information set required for the analysis; furthermore, the evaluation of SEN and SLS can be easily extended to local authorities outside the regression sample making possible a performance analysis for the whole set of LG.

The main weakness of the analysis, instead, is the prerequisite of relying on good measure of outputs, a problem which is common, however, to any kind of performance analysis. Therefore, when the output is not unambiguously measurable, such as in the case of general administrative services or local police services, for example, the results obtained are less robust since output measured in numerical terms does not coincide with the level of public service..

In the final part of the paper, we present an application of the proposed model on the social care sector using detailed data about services provided in 2010 by Italian municipalities. The provision of social care services is a critical sector where outputs can be unambiguously measured (see for more details Section 7), and which absorbs more than $20 \%$ of total municipal current expenditure corresponding to roughly 7 billion euros.

Italian municipalities represent a good laboratory to test our model is motivated by many reasons (see section 6 for more details) essentially based on the recent evaluation of SEN conducted by the Italian central government over the last three years (2011-2013), which represents the beginning of a radical reform of intergovernmental relations and provides us with useful and detailed data about the quality and the quantity of services supplied at the local level.

The rest of the paper is structured as follows: Section 2 develops the theoretical framework; Section 3 discusses, instead, the empirical model used to estimate SEN and SLS; Section 4 provides a detailed analysis of the four quadrant model concluding the exposition of the model. Section 5 provides some background information about the Italian system of municipalities and motivates the choice of Italian data; Section 6 reports the main results obtained applying the model to the social care sector of Italian municipalities; finally section 7 accounts for the main conclusions. All the figures and the tables are displayed in the Appendix.

\section{THE THEORETICAL FRAMEWORK}

Let us consider a country whose local governments (LG), which are democratically elected, provide local public services using, as a source of financing, local taxes levied on resident citizens, being the municipal fiscal 
capacity equalised by the central government ${ }^{5}$. The demand for local public services is expressed during the electoral period. Assuming the validity of the median voter theorem, the electoral competition will lead to the victory of the party whose programme maximises the median voter's utility under its budget constraint reported in equation (1):

$$
\max _{C, G_{e}} u\left(C, G_{e}\right) \text { s.t. } \tilde{R}=\tilde{C}+t \tilde{B} ; t N B=Y
$$

where: $\mathrm{C}$ is private consumption, $G_{\mathrm{e}}$ are local public services (where the subscript e identifies the output as endogenous), $\widetilde{R}$ is the income level, $t$ and $\widetilde{B}$ are respectively the rate and the base of local taxes. All variables, with the exception of the tax rate $t$ refer to the median values related to the local government in question. The level of local taxes, expressed through the tax rate $t$ is announced during the electoral campaign in order to equalise the local government's budget constraint $^{6} . Y$ is the total cost of supplying local public services, $B$ is the average tax base, and $\mathrm{N}$ is the resident population. Thus, the local tax rate is given by the relationship between the total cost of local public services and the overall tax base $\frac{Y}{N B}$.

Solving the problem of the median voter in (1), and assuming that the deviation between the average tax base and the median tax base is modest, we obtain the demand for public services $G_{\mathrm{e}}$ which, expressed in per capita terms, can be expressed as:

$$
g_{e}=d(R, \boldsymbol{Q}, y)
$$

where: $g_{e}=\frac{G_{\mathrm{e}}}{N}, \boldsymbol{Q}$ represents the vector of demographic and socio-economic aspects that characterise the preferences/needs of the citizens and $y$ represents the per capita total cost. ${ }^{7}$

At this point, the locally elected government will be the one that manages to produce $\mathrm{g}_{\mathrm{e}}$ at the lowest possible cost, in order to minimise the tax rate $\mathrm{t}$ and therefore the fiscal burden of the median voter. Maintaining this policy during the

\footnotetext{
5 Among the sources of local government financing, a key role is also played by intergovernmental grants. These are neglected in the model, since they do not impact the decisions of citizens and local administrators, given the hypothesis of full income horizontal fiscal equalization.

${ }^{6}$ In stating the optimal level of local taxes, it is assumed that the candidates adopt a CournotNash strategy, using the choices announced in other jurisdictions as parameters.

7 Moreover, in case of perfect horizontal income equalisation the impact of income $R$ on the demand for local public services should be zero (thus $R$ can disappears from equation (2)), therefore in the empirical analysis a significant relationship between income and output signals the presence of partial horizontal equalisation.
} 
post-electoral period maximises the re-election probability of the incumbent. Moreover, the goal of minimising the input cost is fully justified if we consider Tiebout's hypothesis ${ }^{8}$, which constitutes the pillar supporting many theoretical models for local public finance ${ }^{9}$. Finally, one last justification of the goal of minimising the input cost comes from the budget constraints imposed by the central government. Thus, based on these assumptions, the problem of the local government can be outlined as follows:

$$
\min _{x} t \quad \text { s.t. } \quad t=\frac{\boldsymbol{X}^{\prime} \boldsymbol{P}}{N B} ; \quad G_{e}=g\left(\boldsymbol{X}, \boldsymbol{A}, \boldsymbol{G}_{s}\right)
$$

where $\boldsymbol{X}$ is the vector of inputs and $\boldsymbol{P}$ is the vector of input prices. The obligation to balance the budget and the production function of public services correspond to the two LG's budget constraints. For the production function, it is assumed that the total factor of productivity comprises two variables: $\boldsymbol{G}_{s}$ aimed at capturing the resources employed in the exogenous load factors (e.g. services provided by the local government on behalf of higher level administrations and generally activities not directly attributable to local decisions); and $\boldsymbol{A}$, which captures the impact of exogenous environmental factors on the capacity to produce local public goods (such as congestion phenomena and economies of scale related to the size of the local authority in terms of the resident population) ${ }^{10}$.

Solving the problem of the local government in (3), we obtain the demand functions for inputs and therefore the following per capita cost function for producing public services:

$$
\left(\frac{Y}{N}=\right) y=s\left(\boldsymbol{g}_{e}, \boldsymbol{g}_{s}, \boldsymbol{p}, \boldsymbol{a}\right)
$$

where all variables are expressed in per capita terms (lowercase letters).

In conclusion, the optimal level of local public services and their supply costs (both expressed in per capita terms with respect to the number of beneficiaries

\footnotetext{
${ }^{8}$ According to the hypothesis put forward by Tiebout, the citizens examine the fiscal packages offered by the various jurisdictions and decide to reside in the jurisdiction that offers the best combination of local taxes and public services, from which comes the well-known expression that, based on Tiebout's hypothesis, "citizens vote with their feet".

${ }^{9}$ For a general overview of theoretical models for local public finance, consider: Rubinfeld D.L. (1987), Ross S.L. \& Yinger J. (1999).

10 Lastly, the variable $A$ measures how the production of local public services is impacted by environmental characteristics, where the environment refers, for instance, to both morphological and socio-economic aspects, which do not influence local preferences regarding the level of public services. In essence, these comprise all external elements that can, with other conditions being equal, in some way favour or hinder the supply of local public goods.
} 
designated here as the client group which usually corresponds to the total resident population) are simultaneously determined within a structural model of two equations: (2) and (4). Both the cost and the demand for public services are endogenous variables whose optimal values derive from the interaction between local administrators and citizens, in the process of allocating resources among the public and the private sectors.

Therefore, in order to estimate the relationship between output and expenditure, it is necessary to consider a structural model based on the equations (2) and (4), a very complex econometric approach which requires correct specifications for the demand and the production functions and precise assumptions about the set of regressors used as demand and supply background variables, which should uniquely identify, respectively, the level of output and the cost of public services.

In order to circumvent the problem of output and cost endogeneity we can estimate standard expenditure needs (SEN) and standard levels of services (SLS) following a reduced form approach.

In particular the evaluation of SEN can be obtained estimating an empirical model based on the reduced form of the cost function reported in equation (5) which is obtained substituting equation (2) into (4).

$$
y=f\left(\boldsymbol{Q}, R, \boldsymbol{p}, \boldsymbol{a}, \boldsymbol{g}_{\boldsymbol{s}}\right)
$$

Equation (5) no longer has the properties of a cost function, since it does not include the quantity of local public services among the independent variables. On the other hand, equation (5) expresses the per capita cost for services in relation to all exogenous variables.

The empirical version of equation (5) is usually named expenditure function. The evaluation of SEN thorough the estimation of an expenditure function is the simplest and most robust empirical strategy to follow for estimating SEN in line with the Regression-Based Cost Approach (RCA), and, for this reasons, it is also widespread at the international level

The approach adopted for the computation of the standard level of services (SLS) has been developed along the same line estimating an empirical model based on the reduced form of the demand function reported in equation (6) which is obtained substituting equation (4) into (2).

$$
g_{e}=h\left(\boldsymbol{Q}, R, \boldsymbol{p}, \boldsymbol{a}, \boldsymbol{g}_{s}\right)
$$


Although equation (6) no longer has the properties of a demand function, since it does not include the cost of local public services among the independent variables, equation (6) expresses the per capita quantity of services in relation to all exogenous variables.

The adoption of a reduced-form approach for the estimation of the demand and the supply for local public services has multiple advantages: first of all only exogenous variables are listed among the regressors (e.g. demand background variables, input prices, supply background variables, to exogenous load factors) allowing the use of simple estimators such as Ordinary Least Squares (OLS); moreover, the information set required for the estimation of SEN and SLS is the same, since the same groups of variables are used to evaluate both standard expenditures and standard outputs, thus reducing the dimension of the information set required for the analysis; furthermore, the evaluation of SEN and SLS can be easily extended to local authorities outside the regression sample making possible a comprehensive performance analysis; finally, we do not need to specify the shape of the demand and the supply functions thereby reducing drastically the number of assumptions to be tested for the validity and increasing the robustness of the final results.

\section{THE EMPIRICAL MODEL}

\subsection{THE ESTIMATION OF THE STANDARD EXPENDITURE NEEDS (SEN)}

In order to combine simplicity and robustness of estimates, the valuation of SEN is implemented estimating an empirical model based on the expenditure function reported in equation (5), which represents a reduced form of the structural model of supply and demand for public services.

In particular the estimation of SEN is conducted using the following empirical linear model:

$$
y_{i}=\alpha+\boldsymbol{\beta}^{\prime} \boldsymbol{X}_{i}+\varepsilon_{i}
$$

where: $i$ corresponds to the local authority index; $\alpha$ and $\boldsymbol{\beta}$ are the coefficients to be estimated; $y_{i}$ is the dependent variable corresponding to the current per capita expenditures; $\mathbf{X}_{\mathrm{i}}=\left[\boldsymbol{Q}, R, \boldsymbol{p}, \boldsymbol{a}, \boldsymbol{g}_{\boldsymbol{s}}\right]$ is the vector of independent variables which are used both in the estimation and in the subsequent stage of calculating SEN. $\varepsilon_{i}$ represents the idiosyncratic error term, with zero mean, uncorrelated with $\mathbf{X}_{\mathrm{i}}$, but potentially heterosckedastic. 
The primary advantage of evaluating SEN through the expenditure function is that consistent estimates can be obtained easily and robustly using the OLS estimator (since the independent variables are represented only by exogenous variables) with robust standard errors in order to control for the heteroscedasticity in the covariance matrix. ${ }^{11}$

Once the coefficients of the empirical model of SEN reported in equation (7) have been estimated, the expected values $\left(\hat{y}_{\mathrm{i}}\right)$ of the current expenditure of each LG (also considering those excluded from the regression sample for statistical reasons) are obtained as follows:

$$
\hat{y}_{i}=\hat{\alpha}+\hat{\beta}^{\prime} \boldsymbol{X}_{i}
$$

Subsequently, $\hat{y}_{i}$ can be interpreted as the level of standard expenditures $\left(F S_{i}\right)$ of each LG.

\subsection{THE ESTIMATION OF THE STANDARD LEVEL OF SERVICES (SLS)}

In order to combine simplicity and robustness of estimates, the valuation of SLS is implemented estimating an empirical model based on the reduced form of the demand function reported in equation (6).

Therefore, the empirical model estimated for the evaluation of SLS is very similar to the empirical model used for the evaluation of SEN, the only difference is the dependent variable that here corresponds to the historic quantity of services produced by each LG, while in case of SEN the dependent variable correspond the historic current expenditure.

However, in a multi-output service, such as most of the essential functions carried out by local authorities, $\mathrm{g}_{\mathrm{e}}$ in the equation (6) corresponds to a vector. Therefore, for each output $\mathrm{g}_{\mathrm{ek}}$ of the set $\mathrm{J}$, we should express the demand for local public service as follows:

$$
g_{e k}=h\left(Q_{k}, A_{k}, R_{k}, p_{k}, g_{s k}, G_{k}\right) \quad \forall \quad k=1 \ldots, J
$$

\footnotetext{
11 The following statistical tests have been used to ensure the robustness of the estimates: Cook's distance $($ Cook D), commonly used to estimate the impact of a single observation on OLS coefficient estimates; the leverage points analysis, which identifies the observations most distant from the corresponding fitted values; the coherence of "studentized" residuals (Student R); and the analysis of dfbetas, which examine the observations that significantly influence parameter estimates. In the end, observations identified as outliers or extreme values based on the statistical tests have been eliminated by the regression sample.
} 
where, the suffix $k$ indicates that some of the background variables related to supply and demand, prices and exogenous load factors can be output specific. Moreover, to capture the potential interdependencies between outputs, the vector $\mathrm{G}_{\mathrm{k}}$ comprises the outputs with which $\mathrm{g}_{\mathrm{ek}}$ is correlated.

In the event that the entire set of background variables is common to all outputs, or no interdependencies are detected between outputs, the demand for each output $g_{\text {ek }}$ can be easily estimated through the following empirical model:

$$
g_{e k}=\lambda_{k}^{\prime} X+\varepsilon_{k} \quad \forall \quad k=1 \ldots, J
$$

where, the vector $X^{\prime}=\left[\boldsymbol{Q}, R, \boldsymbol{p}, \boldsymbol{a}, \boldsymbol{g}_{s}\right]$ comprises the exogenous variables explaining the demand for local services, $\varepsilon_{\mathrm{k}}$ corresponds to the i.i.d. error component with zero mean and potentially heteroskedastic, and $\lambda_{\mathrm{k}}$ corresponds to the coefficients that can be properly estimated using the OLS estimator.

If the data confirm the presence of interdependencies among outputs, the model, in order to obtain the unbiased coefficient estimates for $\lambda_{\mathrm{k}}$, has to take on the typical form of the structural model shown in equation (11):.

$$
\begin{aligned}
& g_{e 1}=h_{1}\left(X_{1}, G_{1}\right) \\
& \cdots \\
& g_{e k}=h_{k}\left(X_{k}, G_{k}\right) \\
& \cdots \\
& g_{e J}=h_{J}\left(X_{J}, G_{J}\right)
\end{aligned}
$$

In linear form, the empirical version of the structural model shown in (11) can be rewritten as follows:

$$
\begin{gathered}
g_{e 1}=\lambda_{1}^{\prime} X_{1}+\theta_{1}^{\prime} G_{1}+\phi_{1} \\
\cdots \\
g_{e k}=\lambda_{k}^{\prime} X_{k}+\theta_{k}^{\prime} G_{k}+\phi_{k} \\
\cdots \\
g_{e J}=\lambda_{J}^{\prime} X_{J}+\theta_{J}^{\prime} G_{J}+\phi_{J}
\end{gathered}
$$

where, for each output $g_{e k}$ of the set $J$, an equation is produced in which the vector $X_{k}^{\prime}=\left[\boldsymbol{Q}_{\boldsymbol{k}}, R, \boldsymbol{p}, \boldsymbol{a}, \boldsymbol{g}_{s}\right]$ comprises the exogenous variables which explain the demand for each output, the vector $G_{\mathrm{k}}$ includes the outputs with which $\mathrm{g}_{\mathrm{ek}}$ is correlated, and $\phi_{\mathrm{k}}$ corresponds to the idiosyncratic error component.

In order to estimate the coefficients of the model in equation (12), it is necessary to verify that for each output the vector $X$ contains some background exogenous 
variables that are not present in other equations in order to use them as instrumental variables.

With the availability of a sufficient number of instrumental variables, the estimates for the coefficients $\lambda$ and $\theta$ will be obtained consistently using the Generalized Method of Moments (GMM) estimator, the most commonly used estimator for structural models (Greene (2003), Harris and Màtyàs (1999), Nevo and Whinston (2010), Wooldridge (2002)); in this case it is necessary to verify that the model is "over-identified", i.e. that it presents a number of moments greater than the number of parameters. If the variables available in the dataset do not allow the identification of a sufficient number of instrumental variables, each equation can be alternatively estimated using a Seemingly Unrelated Regressions (SUR) model, ignoring the presence of interdependencies between outputs, and capturing only the interdependence among the stochastic components.

In relation to each output $\mathrm{k}$, once consistent estimates have been obtained for the parameters $\lambda$ and $\theta$, the SLS (or standard outputs) will correspond to the expected values for each equation ( $\left.\hat{\mathrm{g}}_{\mathrm{ek}}\right)$.

We proceed, in conclusion, to aggregate (for each authority) the different measures of output, in order to obtain a composite index of per capita standard outputs $\widehat{M}^{*}$ and a composite index for per capita actual outputs $M^{*}$ corresponding to: 12

$$
\widehat{M}^{*}=\sum_{k=1}^{J} \pi_{k} \hat{g}_{e k}+\sum_{l=1}^{L} \pi_{l} g_{s l}, \quad \quad M^{*}=\sum_{k=1}^{J} \pi_{k} g_{e k}+\sum_{l=1}^{L} \pi_{l} g_{s l}
$$

where the weights $\pi_{k}$ and $\pi_{l}$ will be calculated considering the impact each output exercises on current expenditures estimating a multi-output cost function or using other statistical methodologies for computing composite indicators (consider for example Vidoli and Mazziotta (2013)).

\section{THE MAP OF LOCAL AUTHORITIES}

As illustrated in Figure 1, local authorities can be divided into four groups in relation to two dimensions: the difference between theoretical standard expenditure needs $(F S)$ and per capita actual expenditures $(Y)$ measured on the horizontal axis, and the difference between per capita standard outputs $\left(\widehat{M}^{*}\right)$ and per capita actual outputs $\left(M^{*}\right)$ measured on the vertical axis.

1. The first group comprises authorities for which $\mathrm{M}^{*} \geq \widehat{\mathrm{M}}^{*}$ and FS $\leq \mathrm{Y}$, which can be defined over-standard;

\footnotetext{
12 Note that exogenous load factors $\left(g_{s}\right)$, for which it is not necessary to proceed with an estimate of theoretical values, are also included in the calculation of the composite indices.
} 
2. The second group included those authorities for which $\mathrm{M}^{*} \geq \widehat{\mathrm{M}}^{*}$ and $\mathrm{FS}>Y$, which can be defined efficient;

3. The third group comprises authorities for which $\mathrm{M}^{*}<\widehat{\mathrm{M}}^{*}$ and $\mathrm{FS}>Y$, which can be defined under-standard;

4. The fourth group includes authorities for which $\mathrm{M}^{*}<\widehat{\mathrm{M}}^{*}$ and $\mathrm{FS} \leq \mathrm{Y}$, which can be defined as non-efficient.

The rationale behind the positioning of local authorities in the four quadrants of Figure 1 is based on the consideration that SLS provide a measure of the potential demand corresponding to standard expenditures.

Therefore, a red light comes on for the local authorities in quadrants III and IV of Figure 1: local authorities positioned in quadrant III are designated "under standard" since they present actual expenditures that are lower than the standard expenditures and should satisfy a potential demand that is higher than the current supply capacity; local authorities positioned in quadrant IV are designated "non-efficient" since in addition to facing a potential demand that is higher than the current supply capacity, they present actual expenditures that are higher than standard expenditures. Both these groups of local authorities should be placed under observation: the "under standard" authorities in order to ascertain that by obtaining more financial resources they effectively provide also more services in terms of quantity and/or quality, the "non-efficient" authorities to verify the likely presence of serious inefficiencies (in technical or in allocative terms) in the provision of local services.

On the other hand, a green light comes on for the local authorities situated in the two upper quadrants. Those in quadrant II, defined as "efficient", present a potential demand that is lower than the effectively satisfied one, and standard expenditures that are greater than their actual expenditures. These local authorities should be used as benchmarks for identifying best practices. Lastly, local authorities positioned in quadrant I, defined as "over-standard" are those with actual expenditures that are higher than the standard expenditures, but that prove an actual quantity of output that is also higher than the potential demand. These local authorities should be capable of autonomously financing effective service levels that are higher than potential demand, or of reduce their service levels to bring them in line with their standard expenditures.

The joint analysis of expenditure and output in terms of gaps from the respective standard values is a new measure to test the performance of LG, still at an experimental stage, that in the future can become a simple tool to identify local authorities target of specific policies aimed at improving efficiency in the provision of public services, as well as a simple way to identify the best practices adopted by benchmark local authorities. 
The output-gap and the expenditure-gap can be considered as perfect substitutes, and, in this way, the four quadrants model can be combined with the indifference curves reported in Figure 2 in order to rank the local authorities according to their performance measured in relation to their own standard values in terms of output-gap and expenditure-gap. The substitution rate between output and expenditure to keep the level of performance constants will correspond at the inverse of the unitary cost of output $(m)$. As shown in Figure 2 the level of performance will increase reaching the highest indifference curve towards the north-west quadrant. Moreover, the highest level of performance along the same indifference curve will depend also on the quadrant in the following order: $2,1,3,4$. In the example reported in Figure 2 the ranking of local authorities is as follows: $\mathrm{A}>\mathrm{B}>\mathrm{C}>\mathrm{D}>\mathrm{E}>\mathrm{F}>\mathrm{G}>\mathrm{H}=\mathrm{I}$. In the end, as shown in the figure, a synthetic measure of "cost-result" efficiency can be obtained both in terms of output and in terms of expenditure using the intercept of each indifference curve computed respectively on the vertical axis and the horizontal axis.

From a methodological point of view, this synthetic measure of "cost-result" efficiency can be seen as a directional compensative composite indicator, in which the direction is represented by an average rate of substitution between simple indicators.

Just in case it is not appropriate to impose the perfect compensability between the two gap measures it is always possible to use non-compensatory methods both choosing to impose a direction (see Vidoli et al. (2014)) both not imposing a chosen direction (see De Muro et al. (2010)).

\section{The ChOICE ITALIAN MUNICIPALITIES AND THE SOURCE OF DATA}

Choosing Italian municipalities as a laboratory test for our model can be motivated by many reasons: first of all, Law No. 42 of 5 May 2009 (Enabling Law on fiscal federalism, Law 42/09) and the implementing provisions issued by Legislative Decree No. 216 of 26 November 2010 (Decree 216/10) regarding the valuation of SEN of the local Italian authorities (municipalities and provinces) marked the beginning of a radical reform of intergovernmental relations in Italy starting the path towards the construction of a new mechanism for horizontal fiscal equalisation based on formula-grants; moreover, according to Decree 216/10 the evaluation of SEN is complemented with the construction of a large database on the activities of local authorities which provide, for the first time in Italy, detailed information regarding the quantity and the quality of outputs, a huge amount of data collected through the submission of specific questionnaires to municipalities and provinces thereby providing the possibility to measure accurately the actual level of services supplied by LGs; last but not least, the 
analysis of the levels of services is requested explicitly by Decree 216/10 as a complement of the evaluation of SEN13.

Therefore, in relation to the Italian context, our model may benefit from the huge data collected about local public services. However, at the same time, for the Italian system of fiscal equalisation, our model may represent a useful proposal for the determination of SLS, providing an instrument for measuring the adequacy of the quantity and quality of services provided to the specific local needs. It is important to note that the prerequisite of such an instrument has long been debated in Italy at the political and academic level, but no concrete result has yet been produced.

After three years of intensive data collection and analysis (from 2011 to 2013), in fact, SOSE-Soluzioni per il Sistema Economico S.p.A. ${ }^{14}$, in collaboration with the Instituto per la Finanza e l'Economia Locale ${ }^{15}$ (IFEL ANCI Foundation) ${ }^{16}$, under the supervision of the Commissione Tecnica Paritetica per l'Attuazione del Federalismo Fiscale (COPAFF) ${ }^{17}$ has produced the first wave of the SEN of the essential functions (see Table 1 for more details about the essential functions) of municipalities the ordinary statute regions (6072 local authorities), thus beginning the first essential step towards the design of a new equalisation system no longer linked to the parameter of actual expenditure, which is considered by many as a source of inequity in the distribution of resources and inefficiency in the provision of local services (overall 77 billion euros in 2010 , equal to $5 \%$ of the GDP and $10 \%$ of consolidated public spending). ${ }^{18}$ However, the Italian way toward standard expenditure needs has not yet reached its end, since standard expenditures are now under the examination of the Houses of Parliament, and only after the political consensus will they be used to apportion equalisation grants (see for more details SOSE (2014)).

With regard to municipalities, it is important to emphasise that the valuation of SEN has been managed by dividing four - of the six essential functions (see Table 1) - in ten sub-functions or services in order to adapt the general methodology to the specific supplied services and, thus, achieve high levels of accuracy in the identification of the expenditures of different territories. The valuation of SEN of municipalities, therefore, consists of twelve services; each of which has been

\footnotetext{
13 Standard expenditure needs for each essential function [...] is computed taking into account [...] the identification of organisational models and the level of services provided, determined on the basis of a system of indicators in relation to each essential function and related services (Decree 216/10 Art. 4 par. 1 b))

14 Solutions for the Economic System.

15 Institute for Finance and Local Economy.

16 Union of Italian provinces.

17 COPAFF (Joint technical committee for the implementation of fiscal federalism) is established at the Ministry of Economy and Finance as an intergovernmental forum for sharing financial, economic and fiscal information and supporting the implementation of fiscal federalism.

${ }^{18}$ Expenditure before interests (source ISTAT).
} 
organised into a specific methodological note (for which the acronym reference is shown in parenthesis in the following list).

The general administrative, management and control functions have been divided into four services, for which four separate questionnaires have been developed: tax office (FC01A), technical office (FC01B), civil registry (FC01C), general services (FC01D). Functions concerning public roads and urban transport have been divided into two services with a single questionnaire: public roads (FC04A) and local public transport (FC04B). Planning and environmental functions have been divided into two services with a single questionnaire: land management and planning (FC05A) and waste management (FC05B). Functions concerning social care have been divided into two services with a single questionnaire: general social services (FC06A) and nursery services (FC06B). The following functions have maintained their original uniformity: local police (FC02U) and education (FC03U). Despite the general method being the same for all twelve services, this division has allowed a more precise identification of the independent variables, thus considerably enriching the range of determinants of the overall SEN.

In view of the general unity of the methodological structure it is important to point out that, in relation to the available information and to the nature of the analysed services, in ten cases SEN has been computed using an expenditure function (similar to the one reported in equation 5), while in two cases (complementary education services (FC03U) and nursery services (FC06B)), it was possible to adopt a cost function (similar to the one reported in equation 4) ${ }^{19}$.

Therefore, in order to take our model to the data, we decided to consider the services related to the social care sector and in particular the case of general social services (FC06A) provided by the 6702 municipalities of ordinary statute regions in 2010. In this case, in fact, we can easily compute the expenditure gap taking the difference between the current historic expenditures reported in the 2010 budget accounts (published by the Ministry of Interior ${ }^{20}$ ) and the standard expenditure needs computed by SOSE estimating an expenditure function in line

\footnotetext{
${ }^{19}$ As explained in more details by SOSE (2014), although SOSE has developed, for the evaluation of standard expenditure needs of Italian local authorities (municipalities and provinces) an econometric methodology specific to the Italian system based on the Regression-based Cost Approach (RCA), the distinguishing factor in the choice between the cost and the expenditure function is represented by the characteristics of the variables available to measure the output of services provided for each function. In the majority of cases, in which the output cannot be satisfactorily measured (as it is the case of general services) the valuation of SEN has been carried out through the appraisal of an expenditure function, which links together the actual expenditure with the context variables characterizing the demand of local public services. Only for two specific functions, as we said, in which the issues of output valuation have been easily overcome, the expenditure assessment has been carried out through a cost function, where the actual expenditure is directly linked to the output. In the case of provinces SEN have always been evaluated using an expenditure function.

20 http://finanzalocale.interno.it/apps/floc.php/in/cod/4.
} 
with equations (5) and (7) $)^{21}$, and published by COPAFF on its institutional website $^{22}$ in December 2013. Instead, for the evaluation of the output gap we used the data of the questionnaire FCO6U to obtain a measure of the historic level of services for the year 2010, and a measure of the standard level of services following the procedure described before in Section 3.2. The final results are reported in the following section.

\section{EMPIRICAL ANALYSIS}

\subsection{THE SOCIAL CARE SECTOR}

The social care sector is one of the main function performed by Italian municipalities and absorbs about $20 \%$ of the total actual current expenditure, corresponding to more than 7 billion euros (2010 figures).

Information derived from official sources has been supplemented with accounting and structural data collected through questionnaire FCO6U with reference to the year 2010. The questionnaire, similarly to those implemented for other functions, consists of twelve tables, each with different objectives and content. The top six tables, in particular, contain mainly structural data about managerial choices, staff structure, other inputs employed in the production, and the quality and quantity of services. ${ }^{23}$

Based on the data collected, the services provided in the social care sector have been divided into 11 macro-services (or macro-output): 9 are potentially endogenous with respect to the choices of local administrators: nursery services; early childhood (e.g. other educational and recreational services for early childhood); social emergency (e.g. meals provided by the social canteen); social inclusion (e.g. transport of people with disabilities, literacy courses); income support (e.g. rent allowances); home care (e.g. home care meal service, teleassistance, remote monitoring); day care centres (e.g. recreational social and cultural activities); residential care (e.g. children in foster care, assistance and social rehabilitation); back office activity; 2 can be classified as exogenous load factors: front office services; cemetery, cremation and mortuary services.

${ }^{21}$ Consider SOSE (2014), Section 4, for the details about the estimation of standard expenditure needs related to the social care sector of Italian municipalities.

22 http://www.mef.gov.it/ministero/commissioni/copaff/fabbisogni_standard.html.

23 The remaining six tables are mainly used to collect accounting information aimed at supplementing the information derived from the Budget Sheets in order to evaluate the level of actual expenditures used as dependent variable in the empirical model. In particular, they provide information about the structure of staff cost, the outsourcing, and revenues from the provision of services. Regarding nursery services, for example, questionnaire FC06U provides a wide range of new information about staff structure, the number of children attending part-time and full-time, the number of voucher recipients, opening days and opening hours, the percentage of children using the meal service etc. 
Each macro-output (excluding nursery services) is, in turn, divided into several basic services for a total of 36 elementary output variables.

In consideration of the specific nature of each macro-service, the estimation of SEN has been carried out by separately analysing the nursery services, which have children aged 0-2 as client group, and by grouping the rest of the social services which have the entire resident population as client group within a single category called general social services.

The rest of the analysis will be based on the general social where the valuation of the SEN has been obtained using the expenditure function approach, specifying a linear empirical model, similar to the one specified in equation (7), using as a dependent variable the 2010 current expenditure in per capita terms with respect to the total resident population.

\subsection{THE ESTIMATION OF STANDARD LEVELS OF SERVICES}

As already discussed in the previous section the social care sector is a multioutput function. In particular, as reported in Table 2 the set of general social services is made up of ten macro-outputs.

As shown by Table 2 front office services and cemetery services are considered exogenous load factors, therefore the evaluation of the SLS will be restricted to the estimation of a demand system composed by eight endogenous macro-output: back office, social emergency, income support, day care centres, early childhood, home care, social inclusion and residential care.

Table 2 also reports that, with the exception of back office services, each macrooutput is composed by more than one elementary output variable collected through the questionnaire FC06U. Therefore, as a first step, we computed "first stage" weights in order to aggregate the elementary output variables to obtain a single measure for each macro-output. For example the measure of income support services $I S_{i}$ for each municipality $i$ has been obtained in the following way:

$$
I S_{i}=0.785 X \text { no. of rent allowances } i+0.215 X \text { no. of low income benefits } i
$$

where each weight is obtained rescaling the respective coefficient obtained estimating the impact exerted by each elementary output variable on per capita actual expenditures.

In the case of general social services some of the output variables are correlated, both from the economic and the statistic point of view, as shown by the correlation matrix reported in Table 3. 
Considering the statistical evidence reported in correlation matrix and the indications provided by the experts in the social care sector, the following structural model was identified:

$$
\mid \begin{aligned}
& B O=h\left(\mathrm{HC}, \mathrm{RC}, F O, \boldsymbol{X}_{B O}, \boldsymbol{\lambda}_{B O}, \boldsymbol{\theta}_{B O}\right) \\
& S I=h\left(B O, I S, H C, S E, \boldsymbol{X}_{S I}, \boldsymbol{\lambda}_{S I}, \boldsymbol{\theta}_{S I}\right) \\
& I S=h\left(B O, \boldsymbol{X}_{I S}, \lambda_{I S}, \theta_{I S}\right) \\
& H C=h\left(B O, C M, \boldsymbol{X}_{H C}, \lambda_{H C}, \theta_{H C}\right) \\
& R C=h\left(B O, \boldsymbol{X}_{R C}, \lambda_{R C}, \theta_{R C}\right) \\
& D C=h\left(S I, \boldsymbol{X}_{D C}, \lambda_{D C}, \theta_{D C}\right) \\
& S E=h\left(S I, \boldsymbol{X}_{S E}, \lambda_{S E}, \theta_{S E}\right) \\
& E C=h\left(\boldsymbol{X}_{E C}, \lambda_{E C}\right)
\end{aligned}
$$

In each equation the output variables are expressed in per capita terms and the vectors $\boldsymbol{X}$ comprise the exogenous background demand variables which has been proved statistically significant in the first stage analysis. The large number of contextual variables available from official sources allows us to use some of them as instrumental variables to identify the simultaneous relationships among macro-outputs. In fact, not all the background demand variables has been introduced into the equations of all macro-outputs at the same time, and, as a result, both the order and rank conditions required for the correct identification of the structural model are verified.

The Hausman test rejects the null hypothesis according to which the OLS is a consistent estimator for model's parameters. This result confirms the necessity to take into account the interactions between different macro-outputs and, at the same time, confirms the need to use a set of instrumental variables in order to estimate correctly the interdependencies among outputs.

The linear version of the structural model shown in the equation (13) has been estimated using GMM and coefficients' estimates are reported in the Table 4. Finally, the Hansen $J$ test supports the validity of the instrumental variables which result uncorrelated with the stochastic component of the model.

In the end, the fitted values of the structural model are used to compute the SLS of each macro-output. Subsequently, in order to map the local authorities in the four quadrant of Figure 1, the actual and the estimated values of the 8 macro- 
outputs are aggregated respectively in two scalars as reported in (14): $M^{*}$, the composite indicator of actual outputs, and $\widehat{M}^{*}$, the composite indicator of standard outputs. Both indicators can be interpreted in per capita number of services.

$$
\begin{aligned}
& \widehat{M}^{*}=\pi_{1} \widehat{B O}+\pi_{2} \widehat{S E}++\pi_{3} \widehat{S I}+\pi_{4} \widehat{I S}+\pi_{5} \widehat{H C}+\pi_{6} \widehat{D C}+\pi_{7} \widehat{R C}+\pi_{8} \widehat{E C}+\pi_{9} C M \\
& M^{*}=\pi_{1} B O+\pi_{2} S E++\pi_{3} S I+\pi_{4} I S+\pi_{5} H C+\pi_{6} D C+\pi_{7} R C+\pi_{8} E C+\pi_{9} C M
\end{aligned}
$$

The weights $\pi$ in (14) have been obtained estimating a simple multi-output linear cost function using as dependent variable the same actual per capita current expenditure adopted in the empirical model used to estimate SEN. Coefficients' estimates of the cost functions are provided below in column (1) of Table 5.

The parameters estimated in relation to the endogenous outputs and the exogenous load factors were subsequently re-proportioned to 100 in order to calculate the weights $\pi$ used in the construction of the composite indicators $M^{*}$ and $\widehat{M}^{*}$ as reported in the Table 6 .

\subsection{FINAL RESULTS}

The final results of the valuation of the SLS regarding general social services are summarised in Figure 3 and 4 that visualise the positioning of municipalities in the four quadrants according to the expenditure gap (actual - standard), measured on the horizontal axis in euros per capita, and the output gap (actual standard) measured on the vertical axis in units of aggregate output per 1000 inhabitants. In particular Figure 3 displays the distribution of municipalities aggregated by regions providing clear evidence of the existence of regional models. In line with the expectation, it is important to note that all regions can be found along the diagonal from the south-west quadrant to the north-east corner showing that expenditure levels exceeding the standard are usually associated to the provision of services above the standard in terms of quantity and quality. This is particularly evident for the municipalities of the Emilia-Romagna that can be classified on average over-standard, and for municipalities of Campania that can be classified, instead, under-standard. None of the regions occupy the "nonefficient" quadrant, and the municipalities of Umbria stand out as the most efficient and therefore are the first candidates to be used as benchmark for the provision of social services. Figure 4 display the ranking of regions using the indifference curves between output-gap and expenditure-gap. The slope of the indifference curves correspond to the unitary cost of the aggregate output, which in this case has been estimated equal to 183.72 euros (per 1000 inhabitants). The 
ranking of regions, as well as the measures of efficiency, in terms of expenditure and output, are displayed in Table 7.

\subsection{ROBUSTNESS CHECKS}

As a robustness check, the placement of each municipality in the four quadrants is compared with the level of cost inefficiency computed using Stochastic Frontier Analysis (SFA) techniques.

The first step of this final exercise is to estimate a multi-output frontier cost function using the same linear specification adopted to estimate the weight $\pi$ of each macro-output in the construction of the final composite indicator of output $M^{*}$. The frontier cost function is estimated through maximum likelihood, and the error term is decomposed in two parts in order to separate the idiosyncratic component $(\epsilon)$, which follows a normal distribution, from the cost inefficiency component $(\alpha)$ which follows a half-normal distribution. Point estimates of the coefficients of the the frontier cost function are reported in column (2) of table 5. The percentage of cost inefficiency of each municipality $i$ is computed as $\frac{\alpha_{i}}{y_{i}}$, where $y_{i}$ is the historical expenditure used as dependent variable of the cost function.

The second step is the estimation of three probit models where the dependent variabile is, in turn: a dummy variable which takes value 1 if a municipality exhibits an positive expenditure gap, and 0 otherwise; a dummy which takes value 1 if a municipality exhibits expenditure efficiency above the median, and 0 otherwise; and, finally, a dummy variable which takes value 1 if a municipality is classified in the II quadrant (efficient), and 0 if classified in the $I V$ quadrant (inefficient). On the right hand side of each model the independent variable is a dummy which takes value 1 if a municipality exhibits a percentage of cost inefficiency above the median, and 0 otherwise.

The point estimates of the probit models, reported in table 8, show that for a municipality with a percentage of cost inefficiency above the median we observe that: the probability of having a positive expenditure gap is only $7 \%$ higher than the probability of having a negative expenditure gap, the probability of reporting an expenditure efficiency above the median is, instead, 17\% lower than the probability of showing an expenditure efficiency below the median, the probability of being classified in the II quadrant (efficient) is $26 \%$ lower than the probability of being classified in the IV quadrant (inefficient).

Therefore, the probit estimates reported in table 8 support the validity of our model. They confirms that the level of expenditure efficiency, derived from the segmentation of municipalities in the four quadrants, is indeed a good performance indicator; instead, the expenditure gap alone can not be used to monitor the efficiency of local governments. 


\section{Conclusions}

This paper proposes the evaluation of local governments' performance in the provision of local services using a simple four quadrants model which ranks local authorities according to two dimensions: first the difference between the actual expenditures and the standard expenditures (expenditure gap); second the difference between the actual level of services and the standard level of services (output gap). The policy implications are apparent: this model, combining the estimation of the standard expenditures needs with the computation of the standard level of services, provides a comprehensive evaluation of local authorities using a simple empirical model based on the estimation of the supply and the demand for local services employing a simple reduced form approach, according to which the standard expenditures and the standard level of services are estimated regressing, respectively, the actual current expenditures and the actual level of service over the same set of exogenous context variables. The model also shows that the common econometric techniques employed to estimate local governments' standard expenditure needs can also be adapted to measure the corresponding standard level of local public services.

\section{Acknowledgement}

The authors would like to thank Bruno Chiarini, Ernesto Longobardi, Alberto Zanardi and participants at the CESifo Group Venice Summer Institute 2014, and the XXVI SIEP annual conference for their helpful comments. The usual caveat applies.

\section{REFERENCES}

Afonso, Antonio, \& Fernandes, Sonia (2006), "Measuring local government spending efficiency: Evidence for the lisbon region", Regional studies, 40(1), 39-53.

Audit Commission (2009). Final score: The impact of cpa of local government, 2002-2008. www.audit-commission.gov.uk.

Bergantino A. S., and Porcelli F., (2013). "Housing market prices: capitalisation of efficiency in local public service provision. An application with data on Italian urban transport related expenditures". University of Bari SERIES Working Paper No. 47

Blöchliger H. et al. (2007), "Fiscal equalisation in OECD countries", OECD Network on Fiscal Relations Across Levels of Government.

Boetti L., Piacenza M., Turati G. (2012), "Decentralization and local governments' performance: How does fiscal autonomy affect spending efficiency?", Finanzarchiv: Public finance analysis, 68, 269-302.

Cook, W.D., Roll, Y., Kazakov, A. (1990), "A DEA model for measuring the relative efficiency of highway maintenance patrols", Informational systems and operational research, 28, 113. 
Dafflon B. and Mischler P. (2007), "Expenditure needs equalisation at the local level: methods and practice", in J. Kim and J. Lotz, Measuring Local Government Expenditure Needs, The Copenhagen Workshop.

Daraio and Simar (2007). "Conditional nonparametric frontier models for convex and nonconvex technologies: a unifying approach," Journal of Productivity Analysis, Springer, 28(1):13-32.

De Borger, B., Kerstens, K. (1996), "Radial and nonradial measures of technical efficiency: An empirical illustration for Belgian local governments using an fdh reference technology", Journal of productivity analysis, 7, 5 .

De Muro, P., Mazziotta, M., Pareto, A. (2010) “Composite indices of development and poverty: An application to mdgs", Social Indicators Research, Volume 104, Issue 1, pp. 1-18.

Deller, Steven C. (1992), "Production efficiency in local government: A parametric approach", Public finance, Finances publiques, 47(1), 32-44.

Greene (2003), Econometric Analysis. Prentice Hall, New Jersey, $5^{\text {th }}$ edn.

Grossman P.J., Mavros P. and Wassmer R.W. (1999), Public sector technical inefficiency in large U.S. cities. J Urban Econ 46:278-299.

Harris D. and Màtyàs L. (1999), "Introduction to the Generalized Methods of Moments Estimator," in L. Màtyàs (ed.) Generalized Methods of Moments Estimation. Cambridge University Press.

Haubrich, D. and McLean, I. (2006b). Evaluating the performance of local government a comparison of the assessment regimes in England, Scotland and wales. Policy Studies, 27(4):271-293.

Jayasuriya, Ruwan, Wodon, Quentin. (2003), "Measuring and explaining country efficiency in improving health and education indicators", MPRA Paper 11183. University Library of Munich, Germany.

Lockwood B. and Porcelli F. (2013), Incentive Schemes for Local Government: Theory and Evidence from Comprehensive Performance Assessment in England. The American Economic Journal: Economic Policy, 5(3):1-36.

Martin, S., Downe, J., and Grace, C. (2010). Validity, utilization and evidencebased policy: The development and impact of performance improvement regimes in local public services. Evaluation, 16(31):31- 42.

Nevo A. \& Whinston M. (2010), "Taking the Dogma out of Econometrics: Structural Modelling and Credible Inference," Journal of Economic Perspectives, 24(2), 69-82.

OECD (1981), "Measuring local expenditure needs: the Copenhagen workshop", OECD Urban Management Studies, no. 4.

Porcelli, F. (2011). "Can local governments buy a good performance evaluation? Theory and evidence from the comprehensive performance assessment of English local authorities." (Forthcoming on Applied Economics).

Porcelli F. (2014). "Electoral Accountability and Local Government Efficiency: Quasi-Experimental Evidence From the Italian Health Care Sector Reforms", The Economics of Governance 15(3):221-251. 
Prieto A., Zofio J.L. (2001), "Evaluating effectiveness in public provision of infrastructure and equipment: The case of spanish municipalities", Journal of productivity analysis, 15(1), 41-58.

Reschovsky A. (2007), "Compensating Local Governments for Differences in Expenditure Needs in a Horizontal Fiscal Equalization Program", in R. Boadway and A. Shah, Intergovernmental fiscal grants: Principles and practice, World Bank.

Ross S.L. and Yinger J. (1999), "Sorting and Voting: A Review of the Literature on Urban Public Finance" in P. Cheshire, and E.S. Mills (eds.) Handbook of Regional and Urban Economics, Volume 3, pp. 2001-2060.

SOSE (2014). The Italian way towards Standard Expenditure Needs. www.sose.it

Rubinfeld D.L. (1987), "The Economics of the Local Public Sector" in A. Auerbach and M. Feldstein (eds.) Handbook of Public Economics, Volume 2, pp. 571645.

Vanden Eeckaut, P.J., Tulkens, H., \& Jamar, M.A. (1993), "Cost efficiency in belgian municipalities", in Fried, Lovell and Schmidt "The Measurement of Productive Efficiency. Techniques and Applications", Oxford University Press, New York, Oxford.

Vidoli F., Fusco E., Mazziotta C. (2014) "Non-compensability in composite indicators: a robust directional frontier method", 47 th Scientific meeting of the Italian Statistical Society (SIS), Cagliari.

Vidoli, F., \& Mazziotta, C. 2013. Robust weighted composite indicators by means of frontier methods with an application to European infrastructure endowment. Italian journal of applied statistics, 23(2).

Wooldridge J. (2002), Econometric Analysis of Cross-Section and Panel Data. MIT Press, $1^{\text {st }}$ edn.

Woods, M. and Grubnic, S. (2008). Linking comprehensive performance assessment to the balanced scorecard: evidence from Hertfordshire county council. Financial Accountability and Management, 24(3):343-361.

Worthington A.C. and Dollery B.E. (2000), An empirical survey of frontier efficiency measurement techniques in local government. Local Govern Stud 26(2):23-52. 


\section{APPENDIX}

Figure 1 - Positioning map in relation to the gap between actual expenditures and standard expenditures (horizontal axis) and between actual outputs and standard levels of services (vertical axis)

\section{Service levels (Actual - Standard)}

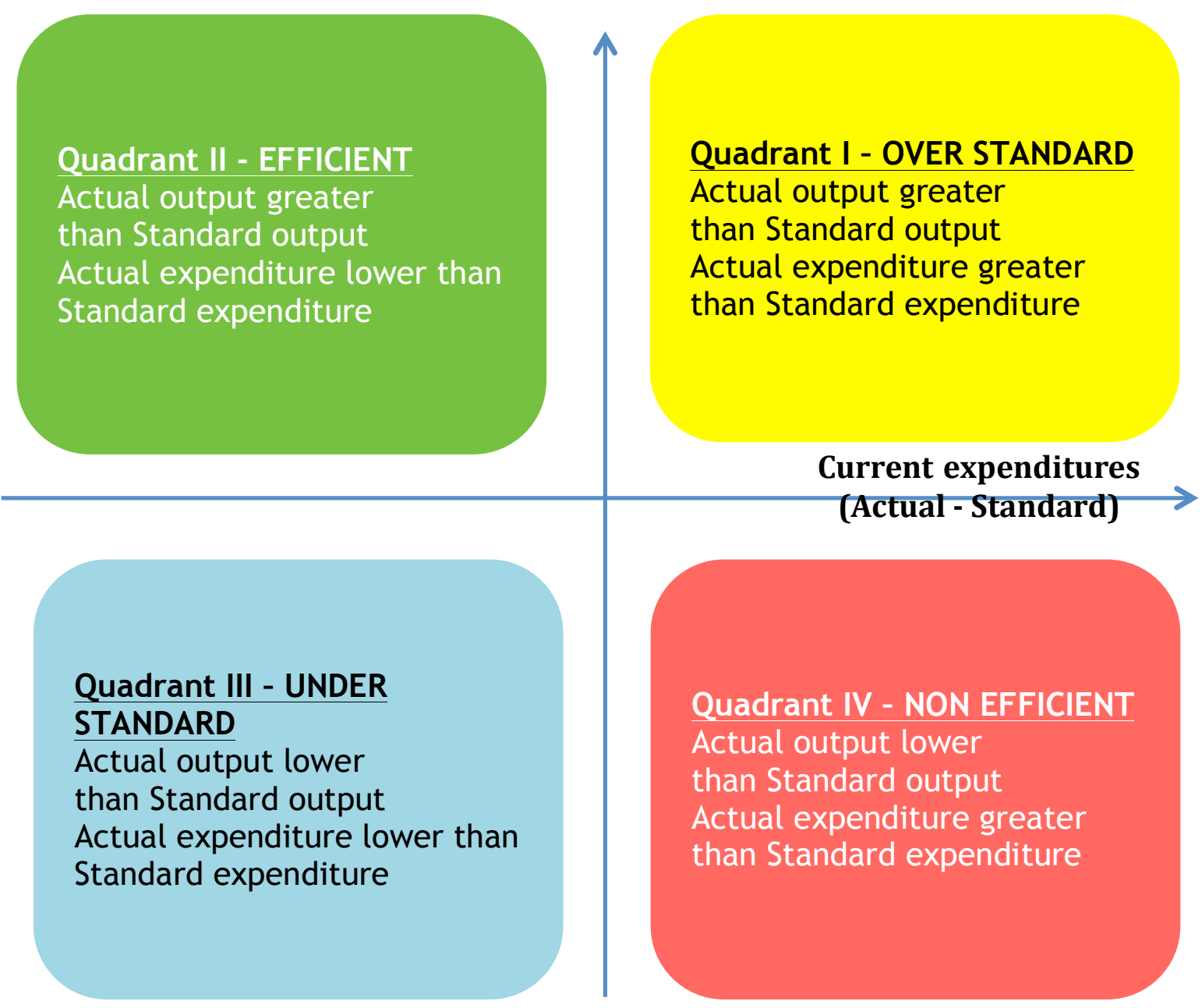


Figure 2 - Ranking of local authorities, indifference curves in relation to the gap between actual expenditure and standard expenditures (horizontal axis) and between actual outputs and standard levels of services (vertical axis)

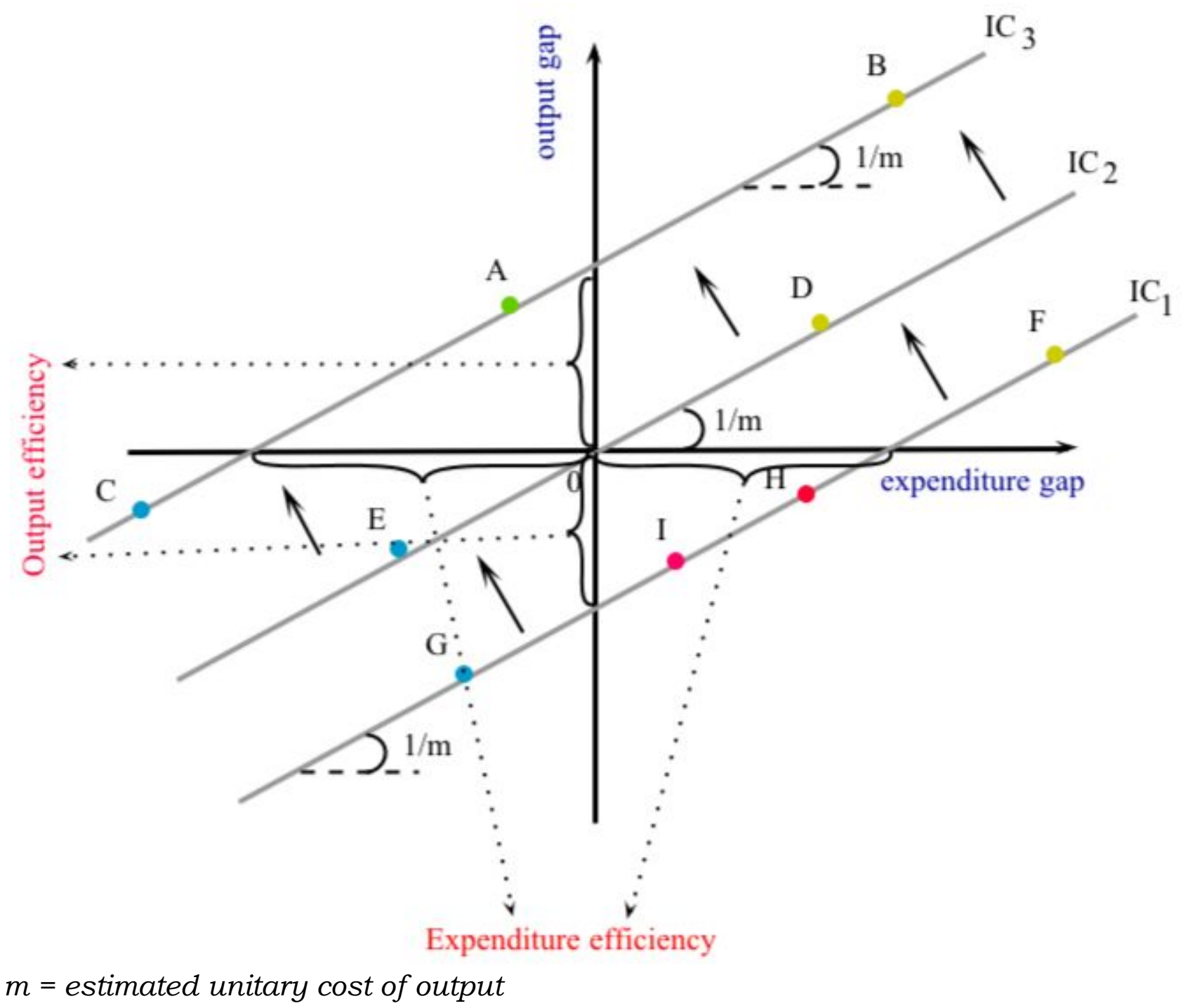


Figure 3 - General social services, positioning map in relation to the gap between actual expenditure and standard expenditures (horizontal axis) and between actual outputs and standard levels of services (vertical axis) - municipalities aggregated by regions

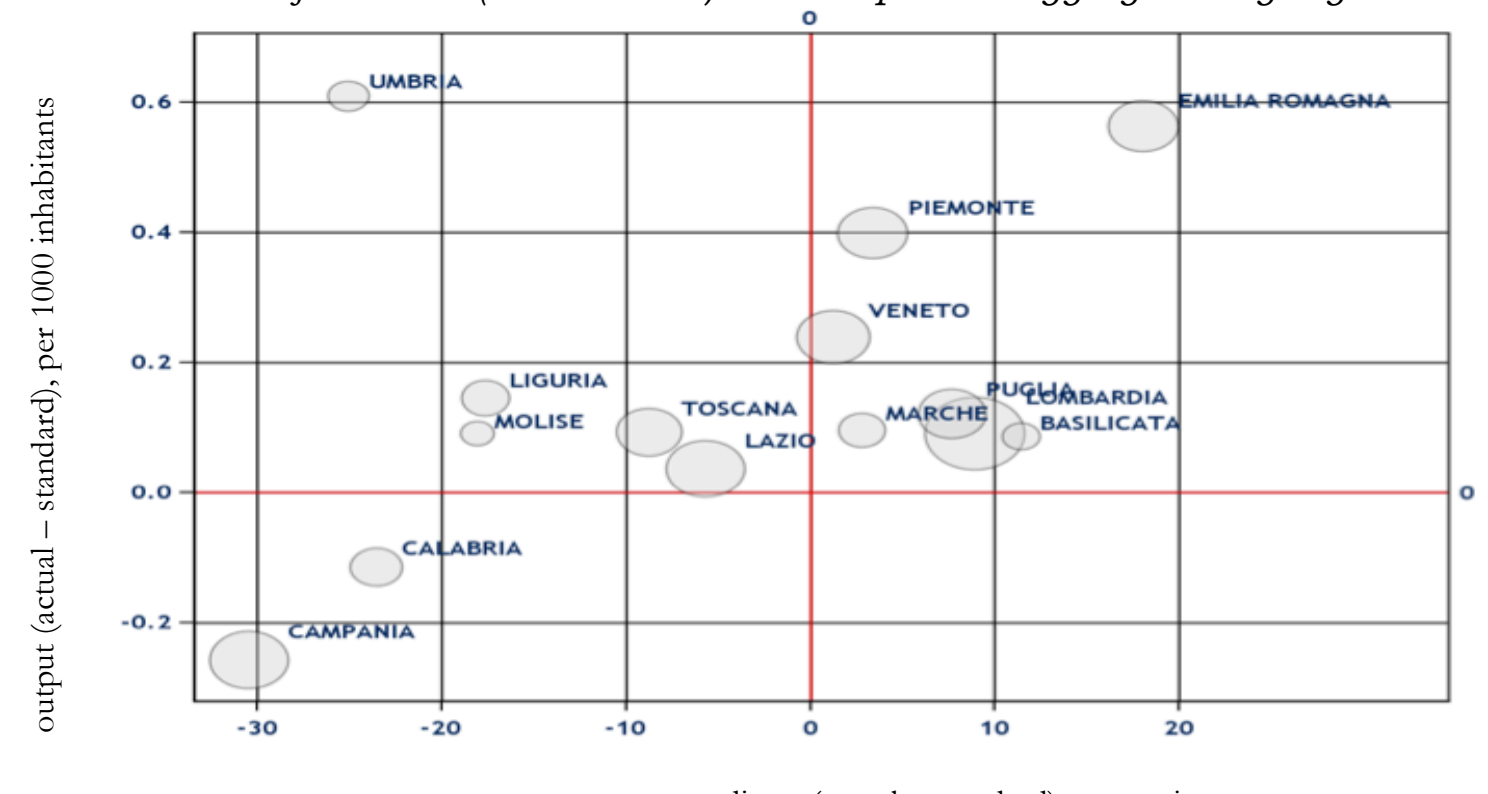

current expenditure (actual - standard), per capita

Dot dimension correspond to the total population.

Abruzzi region has been excluded from the graph because of the expenditure allocated in 2010 for the reconstruction after the 2009 earthquake.

Figure 4 - General social services, ranking of regions, indifference curves in relation to the gap between actual expenditure and standard expenditure needs (horizontal axis) and between actual outputs and standard levels of services (vertical axis) - municipalities above 100000 inhabitants

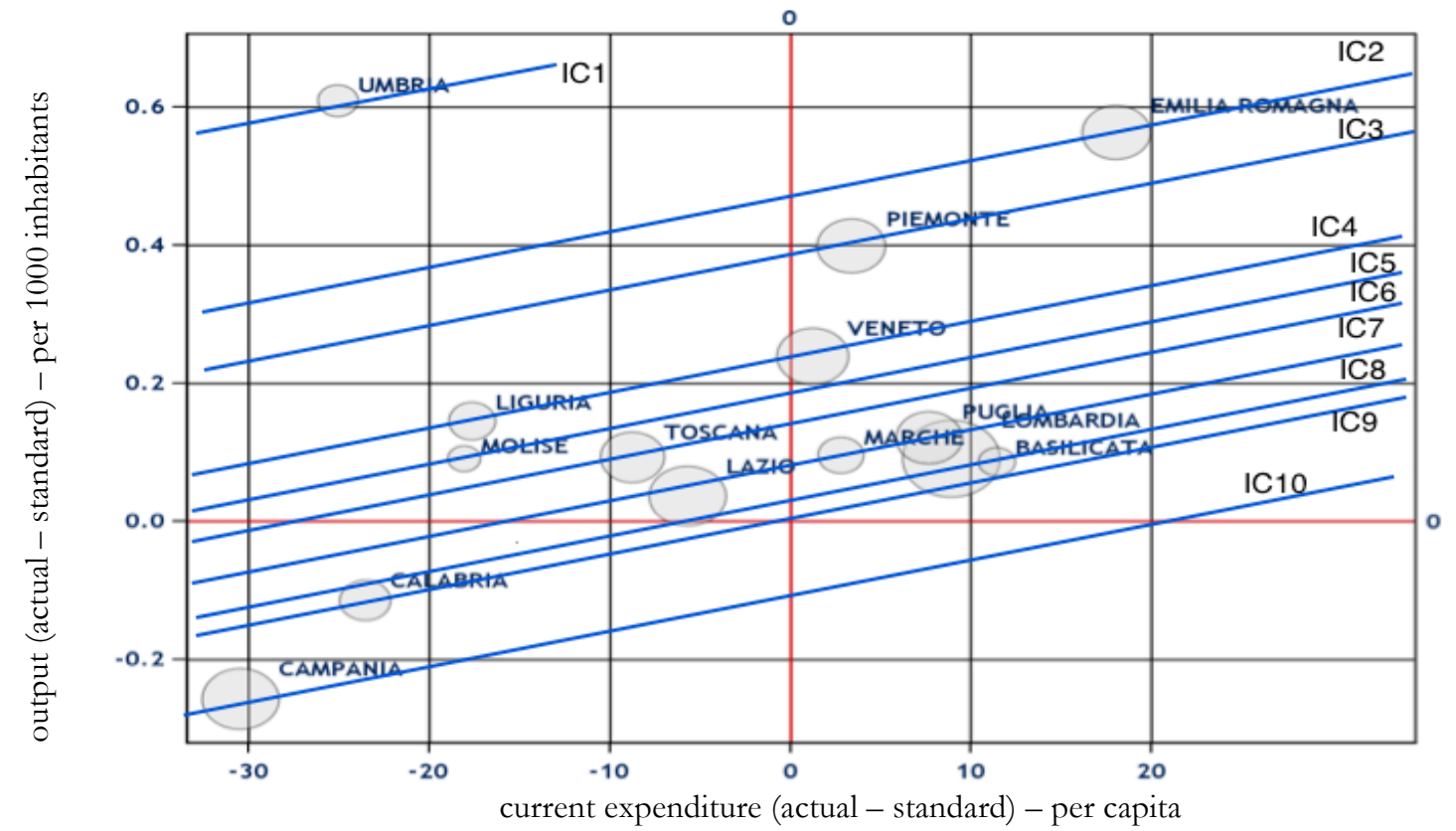

Dot dimension correspond to the total population.

The Abruzzi Region has been excluded from the graph because of the expenditures allocated in 2010 for reconstruction after the 2009 earthquake. 
Table 1 - Distribution of current expenditure allocated on the six essential functions, 2010 Budget Sheets, Municipalities belonging to ordinary statute regions

\begin{tabular}{|l|r|r|}
\hline \multirow{2}{*}{ Essential functions } & \multicolumn{2}{|c|}{$\begin{array}{c}\text { Current expenditure } \\
\text { (Interventions 1,2,3,4,5 and 7)* }\end{array}$} \\
\cline { 2 - 4 } & Amount (euro) & \multicolumn{1}{c|}{ Percentage } \\
\hline General Administrative, Management and Control Functions (only 70\%) & $8,416,198,009$ & $24.83 \%$ \\
\hline Local Police functions & $2,628,769,227$ & $7.75 \%$ \\
\hline Education (complementary services) & $4,343,680,368$ & $12.81 \%$ \\
\hline Public Roads and Transport & $4,266,786,383$ & $12.58 \%$ \\
\hline Planning and Environmental functions & $7,156,941,425$ & $21.11 \%$ \\
\hline Social care & $7,092,667,354$ & $20.92 \%$ \\
\hline Total essential functions & $\mathbf{3 3 , 9 0 5 , 0 4 2 , 7 6 6}$ & $\mathbf{1 0 0 . 0 0 \%}$ \\
\hline
\end{tabular}

*Primary expenditure net of deprecations and extraordinary costs.

Table 2 - General social services, list of macro-outputs.

\begin{tabular}{|c|c|c|c|}
\hline & MACRO-OUTPUT & TYPE & $\begin{array}{c}\text { No. } \\
\text { elementar } \\
\text { y output } \\
\text { variables }\end{array}$ \\
\hline$(\mathrm{FO})$ & Front office & exogenous load factor & 1 \\
\hline$(C M)$ & Cemetery services (e.g. burials, exhumations, cremations) & exogenous load factor & 5 \\
\hline$(B O)$ & Back office & potentially endogenous & 1 \\
\hline$(S E)$ & Social emergency (e.g. meals provided by the social canteen) & potentially endogenous & 2 \\
\hline$(I S)$ & Income support (e.g. rent allowances) & potentially endogenous & 2 \\
\hline$(D C)$ & $\begin{array}{l}\text { Day care centres (e.g. recreational social and cultural activities) } \\
\text { Early childhood (e.g. other educational and recreational services for }\end{array}$ & potentially endogenous & 2 \\
\hline$(E C)$ & $\begin{array}{l}\text { early childhood) } \\
\text { Home care (e.g. home care meal service, tele-assistance, remote }\end{array}$ & potentially endogenous & 2 \\
\hline$(H C)$ & $\begin{array}{l}\text { monitoring) } \\
\text { Social inclusion (e.g. transport of people with disabilities, literacy }\end{array}$ & potentially endogenous & 4 \\
\hline$(S I)$ & $\begin{array}{l}\text { courses) } \\
\text { Residential care (e.g. children in foster care, assistance and social }\end{array}$ & potentially endogenous & 8 \\
\hline$(\mathrm{R} C)$ & rehabilitation) & potentially endogenous & 8 \\
\hline
\end{tabular}

Table 3 - General social services, macro-outputs correlation matrix

\begin{tabular}{|c|c|c|c|c|c|c|c|c|c|c|}
\cline { 2 - 11 } \multicolumn{1}{c|}{} & FO & BO & SE & SI & IS & HC & DC & RC & EC & CM \\
\hline FO & 1 & & & & & & & & & \\
\hline BO & 0.27912 & 1 & & & & & & & & \\
\hline SE & 0.08451 & 0.09110 & 1 & & & & & & & \\
\hline SI & 0.12527 & 0.14403 & 0.14596 & 1 & & & & & & \\
\hline IS & 0.13873 & 0.18786 & 0.09432 & 0.19882 & 1 & & & & & \\
\hline HC & 0.12925 & 0.20779 & 0.09671 & 0.13558 & 0.02185 & 1 & & & & \\
\hline DC & 0.07369 & 0.08606 & 0.03678 & 0.10291 & 0.09124 & 0.08906 & 1 & & & \\
\hline RC & 0.05219 & 0.16573 & 0.02694 & 0.11519 & 0.10238 & 0.13951 & 0.04744 & 1 & & \\
\hline EC & 0.03795 & 0.05529 & 0.01031 & 0.05830 & 0.09645 & 0.03625 & 0.01783 & 0.05487 & 1 & \\
\hline CM & 0.08002 & 0.07014 & 0.01841 & -0.00676 & -0.01365 & 0.12091 & 0.02368 & 0.04507 & -0.00156 & 1 \\
\hline
\end{tabular}


Table 4 - General social services, structural model, GMM coefficients' point estimates (regression sample = 3455)

\begin{tabular}{|c|c|c|c|c|c|c|c|c|}
\hline & \multicolumn{8}{|c|}{ DEPENDENT VARIABLES (output units per 1000 inhabitants) } \\
\hline & Income support & Home care & Social emergency & Residential care & Back office & Social inclusion & Early childhood & Day care centres \\
\hline Back office (per 1000 inhabitants) & 0.05125 & 0.01747 & & 0.00354 & & 0.01253 & & \\
\hline Social inclusion (per 1000 inhabitants) & & & 0.58025 & & 1.68221 & & & 1.31695 \\
\hline Income support (per 1000 inhabitants) & & & & & 51.81783 & 0.03154 & & \\
\hline Home care (per 1000 inhabitants) & & & & & & 0.12407 & & \\
\hline Social emergency (per 1000 inhabitants) & & & & & & 0.04753 & & \\
\hline Foreign resident population (\%) & 0.16830 & 0.01769 & 0.04177 & 0.00398 & & & & \\
\hline Reception for appointment (Dummy, 1 = yes) & 0.55588 & 0.17684 & & & & 0.06886 & & \\
\hline Number of crimes at provincial level (per capita) & 30.49403 & & 16.49683 & & & & & \\
\hline Internal commuters 2001 - (per capita) & 9.20081 & & 1.46546 & & & & & \\
\hline Birth rate $(2008-2010)$ & 0.10979 & & & & & 0.02424 & & \\
\hline Population density (inhabitants per sq-km) X 1000 & 0.37000 & & & 0.01000 & & & & \\
\hline Total employed (per capita) & -3.27735 & 3.92924 & & & & & & \\
\hline Young resident population $(\%<18)$ & & 0.06564 & & 0.00706 & & & & \\
\hline $\begin{array}{l}\text { People with addictions and mental health problems } \\
\text { (per capita) }\end{array}$ & & & 257.40868 & & 401.82879 & & & \\
\hline $\begin{array}{l}\text { Income reported as tax base for the national } \\
\text { personal income tax ( } \% \text { deviation from the sample mean) }\end{array}$ & & & 0.02200 & & & & 0.00180 & \\
\hline Front office (number of users per 1000 inhabitants) & & & & & 75.00749 & & 0.63560 & \\
\hline Total Employees (per capita) & & & & & 11.23147 & & 0.41741 & \\
\hline Number of road accidents (per capita) & 131.21322 & & & & & & & \\
\hline Average number of family members & 1.32562 & & & & & & & \\
\hline $\begin{array}{l}\text { Cemetery services (number of users per } 1000 \\
\text { inhabitants) }\end{array}$ & & 28.85267 & & & & & & \\
\hline Number of social pensions (per capita) & & 28.00428 & & & & & & \\
\hline Total widows and widowers (per capita) & & 6.78644 & & & & & & \\
\hline Illiterate (per capita) & & & 6.31222 & & & & & \\
\hline Offences for drug dealing (per capita) & & & & 29.83623 & & & & \\
\hline Number of single-parent families (per capita) & & & & 5.56650 & & & & \\
\hline Elderly resident population ( $\%$ over 65$)$ & & & & 0.00453 & & & & \\
\hline $\begin{array}{l}\text { Average staff expenditures per employee (weighted } \\
\text { average between internal and external labour cost) } \\
(\% \text { deviation from the sample mean) }\end{array}$ & & & & & -0.02931 & & & \\
\hline Rate of children with disabilities & & & & & & 0.01574 & & \\
\hline Children 3-6, percentage over total population & & & & & & & 3.74188 & \\
\hline $\begin{array}{l}\text { Couples without children aged } 65 \text { or more (per } \\
\text { capita) }\end{array}$ & & & & & & & & 8.84286 \\
\hline Single families - (per capita) & & & & & & & & 2.64485 \\
\hline
\end{tabular}


Table 5 - General social services, cost function, OLS and SFA (Stochastic Frontier Analysis) coefficients' point estimates (all coefficients are expressed in euros, dependent variable = actual current expenditure / total resident population, regression sample = 3399).

\begin{tabular}{|c|c|c|c|c|c|}
\hline & & $\begin{array}{l}\text { OLS } \\
\text { (1) }\end{array}$ & & $\begin{array}{l}\text { SFA } \\
(2)\end{array}$ & \\
\hline CONSTANT & & 32.93 & $* * *$ & 25.63 & $* * *$ \\
\hline \multirow{8}{*}{ ENDOGENOUS OUPUTS } & \multirow{8}{*}{$\begin{array}{l}\text { Back office (per capita) } \\
\text { Social emergency (per capita) } \\
\text { Social inclusion (per capita) } \\
\text { Income support (per capita) } \\
\text { Home care (per capita) } \\
\text { Day care centres (per capita) } \\
\text { Residential care (per capita) } \\
\text { Early childhood (per capita) }\end{array}$} & $39.87 *$ & $* *$ & 15.02 & \\
\hline & & 434.80 & $* * *$ & 446.19 & $* * *$ \\
\hline & & $2083.67 *$ & $* * *$ & 1.922 .20 & $* * *$ \\
\hline & & 753.00 & $* * *$ & 724.21 & $* * *$ \\
\hline & & 2484.58 & $* * *$ & 1.666 .40 & $* * *$ \\
\hline & & 312.24 & $* *$ & 299.69 & $* *$ \\
\hline & & $3968.02 *$ & $* *$ & 2.266 .60 & $* * *$ \\
\hline & & $1633.84 *$ & $* * *$ & 1.188 .60 & $* * *$ \\
\hline $\begin{array}{l}\text { EXOGENOUS LOAD } \\
\text { FACTORS }\end{array}$ & Cemetery services (per capita) & 902.63 & $* * *$ & 692.21 & $* * *$ \\
\hline \multirow{2}{*}{$\begin{array}{l}\text { INPUT PRICES (\% deviation } \\
\text { from the sample mean) }\end{array}$} & \multirow{2}{*}{$\begin{array}{l}\text { Average rents per square meter for commercial use } \\
\text { Average staff expenditures per employee (weighted } \\
\text { average between internal and external labour cost) }\end{array}$} & $0.0870 *$ & $* * *$ & 0.0589 & $* * *$ \\
\hline & & 0.3514 & $* * *$ & 0.3196 & $* * *$ \\
\hline \multirow{3}{*}{$\begin{array}{l}\text { CONGESTION AND } \\
\text { DISECONOMIES OF SCALE }\end{array}$} & \multirow{3}{*}{$\begin{array}{l}\text { population spline (3.000 - } 10.000 \text { inhabitants) } \\
\text { population spline (10.000 - } 50.000 \text { inhabitants) } \\
\text { population spline (100.000 - } 110.000 \text { inhabitants) }\end{array}$} & $0.0015 *$ & $* * *$ & 0.0016 & $* * *$ \\
\hline & & $0.0011 *$ & $* * *$ & 0.0008 & $* * *$ \\
\hline & & $0.0025 *$ & $*$ & 0.0023 & $* * *$ \\
\hline JOINT PROVISION & Unions of municipalities (Dummy, $1=$ yes) & $15.71+$ & $* *$ & 10.784 & $* *$ \\
\hline REGIONAL FIXED EFFECTS & & Yes & & Yes & \\
\hline Lambda (Ou / Ov) & - & & & 4.11 & \\
\hline Likelihood-ratio of $0 \mathrm{u}=0$ : & - & & & $\operatorname{cbibar} 2(01)=$ & $=560$ \\
\hline
\end{tabular}

Robust standard errors, ** P-value $<0.001,{ }^{* *} P$-value $<0.05, * P$-value $<0.1, R$-sq $=0.5135$

Table 6 - General social services, cost function, OLS coefficients' point estimates (all coefficients are expressed in euros, dependent variable $=$ actual current expenditure $/$ total resident population, regression sample $=3455)$.

\begin{tabular}{|ll|c|}
\hline \multicolumn{1}{|c|}{ Weights } & $\begin{array}{c}\text { Re-proportioned } \\
\text { value }\end{array}$ \\
\hline$\pi_{1}$ & Back office & $0.32 \%$ \\
\hline$\pi_{2}$ & Social emergency & $3.45 \%$ \\
\hline$\pi_{3}$ & Social inclusion & $16.52 \%$ \\
\hline$\pi_{4}$ & Income support & $5.97 \%$ \\
\hline$\pi_{5}$ & Home care & $19.70 \%$ \\
\hline$\pi_{6}$ & Day care centres & $2.48 \%$ \\
\hline$\pi_{7}$ & Residential care & $31.46 \%$ \\
\hline$\pi_{8}$ & Early childhood & $12.95 \%$ \\
\hline$\pi_{9}$ & Cemetery services & $7.16 \%$ \\
\hline
\end{tabular}


Table 7 - Ranking of regions and efficiency measures.

\begin{tabular}{|c|c|c|c|c|c|}
\hline Region & type & $\begin{array}{l}\text { output } \\
\text { gap }\end{array}$ & $\begin{array}{c}\text { expenditure } \\
\text { gap }\end{array}$ & $\begin{array}{c}\text { output } \\
\text { efficiency }\end{array}$ & $\begin{array}{l}\text { expenditure } \\
\text { efficiency }\end{array}$ \\
\hline Umbria & efficient & 0.608297 & -25.03331 & 0.7445312 & 136.8091 \\
\hline Liguria & efficient & 0.1445626 & -17.60883 & 0.2403919 & 44.1725 \\
\hline Molise & efficient & 0.0896433 & -18.03279 & 0.1877798 & 34.50493 \\
\hline Toscana & efficient & 0.0925259 & -8.73128 & 0.1400426 & 25.73311 \\
\hline Lazio & efficient & 0.0362694 & -5.667157 & 0.0671108 & 12.33174 \\
\hline Emilia-Romagna & over-standard & 0.5619276 & 18.04468 & 0.4637263 & 85.21066 \\
\hline Piemonte & over-standard & 0.3879 & 3.408072 & 0.3693529 & 67.86935 \\
\hline Veneto & over-standard & 0.2386644 & 1.248775 & 0.2318684 & 42.6063 \\
\hline Marche & over-standard & 0.0951492 & 2.813446 & 0.0798381 & 14.67041 \\
\hline Puglia & over-standard & 0.120406 & 7.690492 & 0.0785534 & 14.43435 \\
\hline Lombardia & over-standard & 0.0903468 & 8.952312 & 0.0416272 & 7.649092 \\
\hline Basilicata & over-standard & 0.0854004 & 11.44955 & 0.0230906 & 4.242948 \\
\hline Calabria & under-standard & -0.1155377 & -23.52248 & 0.0124744 & 2.292196 \\
\hline Campania & under-standard & -0.2587496 & -30.4293 & -0.0931498 & -17.11646 \\
\hline Abruzzo & inefficient & -0.0755843 & 34.93301 & -0.2656938 & -48.82177 \\
\hline
\end{tabular}

Table 8 - Probit point estimates (average partial effects), only municipalities in the SFA regression sample.

\begin{tabular}{|c|c|c|c|}
\hline & \multicolumn{3}{|c|}{ DEPENDENT VARIABLES } \\
\hline & $\begin{array}{c}\text { Dummy variable } \\
\begin{array}{c}1=\text { expenditure } \\
\text { gap }>0 \\
0=\text { expenditure } \\
\text { gap }<0\end{array}\end{array}$ & $\begin{array}{c}\text { Dummy variable } \\
1=\text { expenditure } \\
\text { efficiency }>\text { median, } \\
0=\text { expenditure } \\
\text { efficiency }<\text { media }\end{array}$ & $\begin{array}{c}\text { Dummy variable } \\
\begin{array}{c}1 \text { = II quadrant } \\
\text { (efficient), }\end{array} \\
0=\text { IV quadrant } \\
\text { (inefficient) }\end{array}$ \\
\hline $\begin{array}{l}\text { SFA cost inefficiency dummy } \\
(1=\text { percentage of cost inefficiency above median } \\
0=\text { percentage of cost inefficiency below median })\end{array}$ & $\begin{array}{c}0.0706 \\
{[0.000]^{* * *}}\end{array}$ & $\begin{array}{c}-0.1740 \\
{[0.000]^{* * *}}\end{array}$ & $\begin{array}{c}-0.2626 \\
{[0.000]^{* * *}}\end{array}$ \\
\hline No. of observations & 3399 & 3399 & 1389 \\
\hline
\end{tabular}

$P$-values in brackets, $\quad * * * P$-value $<0.001,{ }^{* *} P$-value $<0.05,{ }^{*} P$-value $<0.1$ 